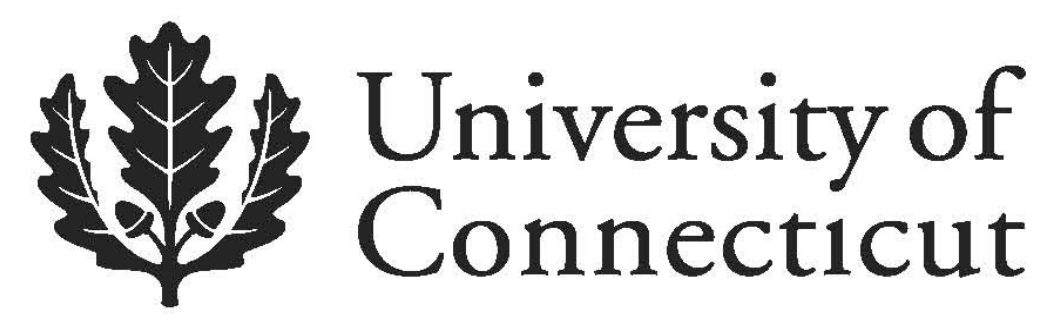

Department of Economics Working Paper Series

Firm Profitability: Mean-Reverting or Random-Walk Behavior?

Giorgio Canarella

California State University, Los Angeles

University of Nevada, Las Vegas

Stephen M. Miller

University of Nevada, Las Vegas

University of Connecticut

Mahmoud M. Nourayi

Loyola Marymount University

Working Paper 2012-05

February 2012

341 Mansfield Road, Unit 1063

Storrs, CT 06269-1063

Phone: (860) 486-3022

Fax: (860) 486-4463

http://www.econ.uconn.edu/

This working paper is indexed on RePEc, http://repec.org/ 


\title{
Firm Profitability:
}

\section{Mean-Reverting or Random-Walk Behavior?}

\author{
Giorgio Canarella \\ California State University, Los Angeles \\ Los Angeles, CA 90032 \\ gcanare@calstatela.edu \\ University of Nevada, Las Vegas \\ Las Vegas, Nevada, USA 89154-6005 \\ giorgio.canarella@unlv.edu \\ Stephen M. Miller* \\ University of Nevada, Las Vegas \\ Las Vegas, Nevada, USA 89154-6005 \\ stephen.miller@unlv.edu \\ Mahmoud M. Nourayi \\ Loyola Marymount University \\ Los Angeles, CA 90045 \\ mnourayi@lmu.edu
}

\begin{abstract}
We analyze the stochastic properties of three measures of profitability, return on assets $(R O A)$, return on equity $(R O E)$, and return on investment $(R O I)$, using a balanced panel of US firms during the period 2001-2010. We employ a panel unit-root approach, which assists in identifying competitive outcomes versus situations that require regulatory intervention to achieve more competitive outcomes. Based upon conventional panel unit-root tests, we find substantial evidence supporting mean-reversion, which, in turn, lends support to the long-standing "competitive environment" hypothesis originally set forward by Mueller (1976). These results, however, prove contaminated by the assumption of cross-sectional independence. After controlling for cross-sectional dependence, we find that profitability persists indefinitely across some sectors in the US economy. These sectors experience extremely slow, or non-existent, mean-reversion.
\end{abstract}

Key words: Cross-sectional dependence, unit roots, panel data, hysteresis, firm profitability

JEL codes: C23, D22, L25

* $\quad$ Corresponding author. 


\section{Introduction}

Theoretical microeconomic models use a representative firm to describe an industry, assuming

firm homogeneity. Empirical evidence, however, facilitated by the more-recent availability of

firm-level data, shows that firms exhibit heterogeneity, even for a narrowly defined industry.

That is, industries display substantial and persistent differences in productivity (Nelson and

Winter, 1982), innovation (Griliches, 1986), skill compositions and wages (Haltiwanger et al., 2007), profitability (Mueller, 1977, 1986), and so on. ${ }^{1}$

The extent of profit persistence, in particular, remains an open question in empirical micro-econometrics. That is, important issues relate to the stochastic behavior of firm profits. Do firm profits exhibit mean-reverting or random-walk behavior? If firm profits revert to the mean (i.e., stationary process), then shocks that affect the series prove transitory, implying that profits eventually return to their equilibrium level. ${ }^{2}$ Researchers call the mean-reversion (stationarity) of profit as the "competitive environment" hypothesis (Mueller, 1986). ${ }^{3}$ The "competitive

\footnotetext{
${ }^{1}$ The persistence of differences in productivity, skills, wages, and profits may reflect a common source. That is, productive firms employ skilled workers and pay high wages (e.g., Haltiwanger et al., 1999). In addition, worker skills positively correlate with the market value of the firm (Abowd et al., 2005). As suggested by Haltiwanger et al. (2007), the assignment model provides a potential explanation for the coexistence of persistent differences in several variables. If a quasi-fixed firm-specific resource and workers skills complement each other, a firm endowed with large resources may willingly pay high wages to attract skilled workers. Such a firm achieves high productivity and earns large profits.

${ }^{2}$ Marshall thought that this assumption did not hold in actual market processes. Using the shock to the supply of cotton during the American Civil War as an example, he argued that ". . . if the normal production of a commodity increases and afterwards diminishes to its old amount, the demand price and the supply price are not likely to return, as the pure theory assumes that they will, to their old positions for that amount" (Marshall, 1890, 426).

${ }^{3}$ Essentially two distinct views exist at the core of the "competitive environment" hypothesis, static and dynamic views of competition (Gschwandtner, 2012). The static view's long history in empirical economics begins with the seminal analysis of Bain $(1951,1956)$ and extends through the work of Schwartzman (1959), Levinson (1960), Fuchs (1961), Weiss (1963), Comanor and Wilson (1967), Collins and Preston (1969), and Kamerschen (1969), among others. In the static view, persistent differences across firms reflect the characteristics of the industry, such as industry concentration and industry elasticity of demand. Profits persist because significant barriers to entry exist. Conversely, the dynamic view, which links to the work of Schumpeter $(1934,1950)$, focuses on the characteristics of the firms, in particular their innovative capacities. Innovations create monopoly power. Firms benefit from their "first mover" advantages (e.g., Spence, 1981; Lieberman and Montgomery, 1988) and increase their market power over time. In theory, entry and the threat of entry eliminates such abnormally high profits, while firms that make abnormally low profits restructure or exit the industry. Although the process of "creative destruction" should drive
} 
environment" hypothesis characterizes the dynamics of firm profits as a stationary, meanreverting, stochastic process. The existing literature on profit persistence generally follows the mean-reverting view of firm profits. Conversely, if firm profits exhibit random-walk or hysteretic behavior (i.e., profits evolve as a unit-root, non-stationary, integrated process), shocks affecting the series exhibit permanent effects, shifting equilibrium profit from one level to another.

A unit-root process imposes no bounds on how a variable moves. If firm profits really conform to random-walk processes, then these profits are also non-predictable. This, in turn, suggests, from an antitrust and regulatory perspective, that policy recommendations based on profitability may prove advisable, as current profitability no longer is a transitory phenomenon and competition fails to control the adjustment or mean-reversion of firm profits toward some long-run equilibrium value. Thus, evidence on the stochastic properties of profitability can assist in differentiating between instances of a competitive environment, and instances which may require regulatory intervention to achieve a competitive environment.

Evidence on the stochastic properties of profitability also possesses well-defined implications for econometric modeling and forecasting. Failure to reject the unit-root hypothesis potentially implies that profitability exhibits a long-run cointegrating relationship with other firm-level data, while rejecting the unit-root hypothesis implies that profitability exhibits only a short-term relationship with other corporate series. Rejecting or not rejecting the unit-root hypothesis, in turn, profoundly affects the forecasting process, since forecasting based on a mean-reverting process proves quite different from forecasting based on a random walk process.

Tippett (1990) models financial ratios in terms of stochastic processes, and Tippett and

all firms' economic profits toward zero, the "first-mover" advantages and other entry and exit barriers may impede firms reaching this point. Therefore, the dynamic view is consistent with non-zero economic profits at different points in time. 
Whittington (1995) and Whittington and Tippett (1999) report empirical evidence that the majority of financial ratios exhibit random-walk behavior. Siddique and Sweeney (2000) present panel evidence that the return on equity $(R O E)$ and return on investment $(R O I)$ are integrated, I(1), processes. The ROE provides a crucial component to the Edwards-Bell-Ohlson (Ohlson, 1995) accounting valuation model; the ROI proves a crucial variable in the Free-Cash-Flow (FCF) finance valuation model. These models typically assume that $R O E$ and $R O I$ are meanreverting, stationary, stochastic processes (Dechow, et al. 1999) because if competition eliminates economic profits over time, these financial ratios must revert to their required rates of return.

Profit hysteresis should not be confused with profit persistence. Profit persistence entails a slow process of adjustment to the equilibrium level, while profit hysteresis implies that firm profits may deviate from their normal level and never return to it. Thus, hysteresis implies that firm profits exhibit a unit root, while persistence suggests that firm profits exhibit a near unit root. $^{4}$

The methodology typically applied to analyze persistence of firm profits uses a firm-level first-order autoregressive model. ${ }^{5}$ Since the seminal contributions of Mueller $(1977,1986)$, many others, such as Geroski and Jacquemin (1988), Schwalbach, et al. (1989), Cubbin and Geroski (1990), Mueller (1990), Jenny and Weber (1990), Odagiri and Yamawaki (1986, 1990), Schohl (1990), Khemani and Shapiro (1990), Waring (1996), and Glen, et al. (2001), find evidence of persistence of firm profits. Lipczinsky and Wilson (2001) summarize these studies and their

\footnotetext{
${ }^{4}$ The literature on hysteresis in unemployment and international trade uses a similar approach. See, for example, Gordon (1989) and Franz (1990).

${ }^{5}$ The $A R(1)$ model incorporates the idea that competitive mechanisms need some time to erode the excess profits generated by short-run rents (Mueller, 1986). Geroski (1990) justifies the autoregressive specification theoretically as a reduced form of a two-equation system, where firm profits depend on the threat of entry into the market, and the threat, in turn, depends on the profits observed in the last period.
} 
findings.

All studies specify a common empirical model -- a univariate $A R(1)$ process as follows:

$$
\pi_{i t}=\alpha_{i}+\lambda_{i} \pi_{i t-1}+\mu_{i t}
$$

where $\pi_{i t}$ is the (normalized) profit of firm $i$ in period $t, \alpha_{i}$ is a firm specific constant, $\lambda_{i}$ is the parameter that indicates the speed of convergence of profit to a mean value (equilibrium rate of return), and $\mu_{i t}$ is an error term distributed $N\left(0, \sigma^{2}\right)$. The $A R(1)$ structure implies that the maximum speed of mean-reversion occurs when $\lambda_{i}=0$. The model is estimated by $O L S$ for each firm $i$ and an estimate of the long-run profit $\left(\bar{\pi}_{i}=\pi_{i t}=\pi_{i t-1}\right)$ of each firm is given as follows: ${ }^{6}$

$$
\bar{\pi}_{i}=\frac{\alpha_{i}}{1-\lambda_{i}}
$$

If all firms earn the competitive rate of profit, then $\bar{\pi}_{i}$ should equalize for all firms (ignoring differences in risk). ${ }^{7}$ This long-run profit captures the static notion of the competitive environment. The dynamic notion of the competitive environment, however, focuses on the parameter estimate of $\lambda_{i}$. If $\lambda_{i}$ is close to zero, then firm profits display minimal persistence: profits at time $t-1$ do not exert much effect on profits at time $t$. On the other hand, if $\lambda_{i}$ is close to 1, then firm profits exhibit high persistence: profits at time $t-1$ exert a substantial effect on profits at time $t$.

This approach, however, experiences severe limitations, since the methodology assumes stationary processes. That is, $\bar{\pi}_{i}$ does not exist for unit-root processes where $\lambda_{i}=1$, the degenerate case of adjustment dynamics. Kambhampati (1995), Goddard and Wilson (1999),

\footnotetext{
${ }^{6}$ The $\alpha_{i}$ includes a competitive profit and a firm-specific permanent rent over and above the competitive return. See Gschwandtner (2012).

${ }^{7}$ Any firm-specific permanent rent must equal zero.
} 
Gschwandtner (2005), among others, using univariate tests, and Yurtoglu (2004), Bentzen, Madsen, et al. (2005), Resende (2006), Aslan, et al. (2010), and Aslan, et al. (2011), using panel unit-root tests, report partial evidence that supports unit-root processes.

More recent research, such as Gschwandtner (2012), Gschwandtner and Hauser (2008), Stephan and Tsapin (2008), Cuaresma and Gschwandtner (2008), McMillan and Wohar (2011), and Goddard, et al. (2004), among others, departs from the OLS autoregressive method. Gschwandtner (2012), using a state space $A R(1)$ model, finds time-varying profit persistence. Gschwandtner and Hauser (2008), using a fractional integration method, report evidence of nonstationarity. Stephan and Tsapin (2008), employing Markov chain analysis and Generalized Methods of Moments (GMM) estimation, find that Ukrainian firms do not significantly differ from the findings for firms in more advanced economies. Cuaresma and Gschwandtner (2008) report low levels of persistence, using a non-linear threshold model that allows for non-stationary behavior over sub-samples. McMillan and Wohar (2011), applying an asymmetric autoregressive model, find that firm profits above normal persist longer than firm profits below normal. Goddard, et al. (2004) use the Arellano and Bond (1991) approach to estimate a dynamic panel model of profitability of European banks and find that profits exhibit significant persistence despite the presence of substantially increased competition in the industry.

In this paper, we depart from the firm-level autoregressive approach and focus on testing for the existence of a unit root in a linear process. ${ }^{8}$ Specifically, we test for the validity of the

\footnotetext{
${ }^{8}$ Pérez-Alonso and Di Sanzo (2011) acknowledge that a unit root provides the necessary, but not sufficient, condition for the existence of hysteresis, since the unit-root process could reflect the accumulation of natural shocks and not depend on whether hysteresis exists. Following the vast majority of the empirical literature in this area, we adopt linear hysteresis as described by the presence of unit roots. We recognize, however, that this adopts a potentially narrow definition, since the linear hysteretic hypothesis is a special case of a more general hysteresis case. Cross, et al. (2009) note that a general hysteretic process contains two features -- eminence (i.e., positive and negative shocks of equal size do not cancel each other) and selective memory of past shocks (i.e., only the "nondominated extreme values" of the shocks are retained in the memory). The linear hysteretic hypothesis, in contrast, does not have "non-dominated extreme values" and two consecutive shocks of equal magnitude and opposite
} 
hysteresis hypothesis, using panel unit-root tests. By using such tests rather than univariate tests, we combine information from time series with information from cross-sectional units, improving estimation efficiency and potentially producing more precise parameter estimates. Furthermore, panel unit-root tests possess asymptotically standard normal distributions. This contrasts with conventional time-series unit-root tests, which possess non-standard normal asymptotic distributions. On the other hand, the advantages of micro-econometric panels are often overstated, since such data exhibit many cross-sectional and temporal dependencies. That is, " $N T$ correlated observations have less information than NT independent observations" (Cameron and Trivedi, 2005, p. 702).

Conventional panel unit-root tests, such as Levin, et al. (2002), Harris and Tzavalis (1999), and Im, et al. (2003) receive criticism (O’Connell, 1998; Jönsson, 2005; and Pesaran, 2007, among others) for assuming cross-sectional independence. Cross-sectional dependence can arise due to unobservable common stochastic trends, unobservable common factors, common macroeconomic shocks, spatial effects, and spillover effects, which are common characteristics of the datasets employed in industry studies. Furthermore, Baltagi and Pesaran (2007) and Pesaran (2007) argue that ignoring the presence of cross-sectional dependence in panel unit-root tests leads to considerable size distortions and can cause adverse effects on the properties of tests, leading to invalid and misleading conclusions.

This paper contributes to the existing profit persistence literature in three ways. First, we deal with the low-power and size-distortion problems (Luintel, 2001; Strauss and Yogit, 2003; Pesaran, 2007) of conventional panel unit-root tests by employing a panel-data unit-root

direction will cancel each other. As Leon-Ledesma and McAdam (2004) point out, however, we can use hysteresis interpreted as a unit root as a local approximation to the underlying data generating process (DGP) of profits during a sample period. Consequently, unit-root tests for the presence of the linear version of the hysteresis hypothesis supplies an upper-bound test of the hypothesis, given that this is an extreme case of path-dependence, where any shock, large or small, matters. 
methodology that relinquishes the assumption of cross-sectional independence. Second, we use a large panel data of public firms in the US from 2001 to 2010. Most empirical literature on profit persistence does not include data after 2000. This may prove important, given the turbulence over the sample period with its various "bubbles" and substantial turnover of firms. In addition, we further partition the panel into ten sectors of the economy (using the classification by Standard and Poor's Compustat) and examine the stochastic properties of profitability in each sector. By stratifying by sector, our profit persistence tests use the average industry profit as the benchmark rather than economy-wide average profit. In other words, we measure firm profit as a deviation from the average industry profit. Since each sector may exhibit a different level of competitive profit, our measure of profit makes it more likely that our tests will support the competitive environment hypothesis. Third, we measure profitability with three of the most extensively used measures: return on assets (ROA), return on equity (ROE), and return on investment (ROI). Most research in this field uses only data on returns on assets $(R O A)$.

Application of conventional panel unit-root tests finds strong evidence that favors the mean-reverting hypothesis in each of the three measures of profitability. These tests, however, assume cross-sectional independence. We strongly reject this assumption with the $C D$ test (Pesaran, 2004). Moreover, the application of the Pesaran (2007) CADF unit-root test uncovers substantial evidence of linear hysteretic behavior in each of the three measures of profitability, which refutes the "competitive environment” hypothesis.

The rest of the paper is organized as follows. After a brief review of panel unit-root tests that assume cross-sectional independence, Section 2 describes the approach developed by Pesaran $(2004,2009)$ to test for cross-sectional independence (CD test) and to test for panel unit roots with cross-sectional dependence (CADF test). Section 3 reports the findings. Section 4 
presents the conclusions.

\section{Empirical methodology}

We can examine the linear hysteretic hypothesis by means of panel unit-root tests, where the null hypothesis implies a unit root. Assume that, for a sample of $N$ firms observed over $T$ time periods, $r_{i t}$ exhibits the following augmented Dickey-Fuller (ADF) representation:

$$
\Delta r_{i t}=\alpha_{i}+\rho_{i} r_{i t-1}+\sum_{j=1}^{p_{i}} \gamma_{i j} \Delta r_{i t-j}+\varepsilon_{i t}
$$

where $r_{i t}$ denotes the profit series (ROA, ROE, or $\left.R O I\right), \Delta r_{i t}=r_{i t}-r_{i t-1}, \alpha_{i}$ is the intercept term that captures the firm-specific effects, and $\varepsilon_{i t} \sim N\left(0, \sigma_{i j}^{2}\right)$. To incorporate the time-specific effects, we add a trend component to Equation (3) as follows:

$$
\Delta r_{i t}=\alpha_{i}+\rho_{i} r_{i t-1}+\delta_{i} t+\sum_{j=1}^{p_{i}} \gamma_{i j} \Delta r_{i t-j}+\varepsilon_{i t}
$$

When $\rho_{i}<0$, the processes for $r_{i, t}$ defined by equations (3) and (4) are stationary, and firm profits are mean-reverting. On the other hand, when $\rho_{i}=0$, the processes for $r_{i, t}$ defined by equation (3) and (4) contain a unit root, and firm profits follow a random walk and display pathdependence. $^{9}$

In recent years, the econometric literature developed a number of unit-root tests in panel data. $^{10}$ Two groups of tests exist, depending on the alternative hypothesis. The first group (e.g., Levin, et al., 2002; Harris and Tzavalis, 1999) assumes homogeneity of autoregressive

\footnotetext{
${ }^{9}$ Madsen (2010) observes that equations (3) and (4) contains two sources of persistence -- the autoregressive mechanism described by $\rho_{i}$ and the unobserved individual-specific effects described by $\alpha_{i}$. A lower $\rho_{i}$ means that more persistence associates with the autoregressive mechanism and less persistence associates with the unobserved individual-specific effects. The case with $\rho_{i}=0$ is the extreme case where all persistence falls on the autoregressive mechanism.

${ }^{10}$ For a general survey of the literature about unit root tests, see Breitung and Pesaran (2008).
} 
coefficients (i.e., $\rho_{1}=\rho_{2}=\ldots=\rho_{N}=\rho$ ) and tests the null hypothesis $H_{0}: \rho_{i}=\rho=0$ against the alternative hypothesis $H_{1}: \rho_{i}=\rho<0$ for all $i$. The second group (e.g., Im, et al. 1997, 2003) does not assume a common unit-root process. Rather, it allows for heterogeneity in all parameters and tests the null hypothesis $H_{0}: \rho_{i}=0$ against the alternative hypothesis $H_{1}: \rho_{i}<0$ for $i=1, \ldots, N_{1}$ and $\rho_{i}=0$ for $i=N_{1}+1, \ldots, N$. We confine our attention to those tests, which are more appropriate for small $T$ and large $N$.

Consider the Harris and Tzavalis (1999, HT) test. This test is based on bias correction of the within-group (WG) estimator under the null. The $H T$ test assumes that the number of panels $N$ tends to infinity for a fixed number of time periods $T$ and allows for non-normality but requires homoskedasticity. The normalized distribution of the HT test statistic depends on the assumptions made about the deterministic constant and trend. When the DGP includes heterogeneous fixed effects and no trend, ${ }^{11}$ the test statistic equals $\sqrt{N}\left(\hat{\rho}_{W G}-1-B_{2}\right)$, which is asymptotically normally distributed with $\mu=0$ and $\sigma^{2}=C_{2}$, where $\hat{\rho}_{W G}$ equals the $W G$ estimator, $B_{2}=-3(T+1)^{-1}$, and $C_{2}=3\left(17 T^{2}-20 T+17\right)\left(5(T-1)(T+1)^{3}\right)^{-1}$. On the other hand, when the DGP includes heterogeneous fixed effects and individual trends, the test statistic equals $\sqrt{N}\left(\hat{\rho}_{W G}-1-B_{3}\right)$, which is asymptotically normally distributed with $\mu=0$ and $\sigma^{2}=C_{3}$, where $B_{3}=-15(2(T+2))^{-1}$ and $C_{3}=15\left(193 T^{2}-728 T=1147\right)\left(112(T-2)(T+2)^{3}\right)^{-1}$. In the first case, the null hypothesis is a non-stationary process while the alternative is a stationary process, where both hypotheses include heterogeneous intercepts. In the second case, the null hypothesis is a non-stationary process while the alternative is a stationary process, where both hypotheses

\footnotetext{
${ }^{11}$ Harris and Tzavalis (1999) consider three models when testing for the unit-root hypothesis. They differ on the deterministic component specified under the alternative. The first model excludes both the constant and the individual trend, the second model includes the constant only, and the third model includes both constant and trend.
} 
include heterogeneous constants and a deterministic trend.

The Levin, et al. (2002) test, which requires that the ratio of the number of panels to time periods tends to zero asymptotically, performs poorly for a large number of panels and relatively few time periods. Thus, our sample with a relatively large number of panels to time periods precludes us from considering this test.

Now, consider the Im, et al. $(1997,2003$, IPS) test. This test takes a different approach from the $H T$ test, in that it views the panel-data regression as a system of $N$ individual regressions and the test combines independent Dickey-Fuller tests for these $N$ regressions. The test allows the $\rho_{i}$ values to differ over cross-sections, but assumes that $N_{1}$ of the $N$ panels are stationary with individual specific autoregressive coefficients. Following the estimation of individual $A D F$ regressions, the test adjusts the average of the $t$ statistics for $\rho_{i}$ to obtain the test statistic:

$$
\bar{t}_{N T}=N^{-1} \sum_{i=1}^{N} t_{i T}
$$

where $t_{i T}$ equals the individual Dickey-Fuller test statistic for testing $\rho_{i}=0$. Im, et al. (1997, 2003) show that the standardized test statistic:

$$
\bar{Z}=\sqrt{N} \frac{\left(\bar{t}_{N T}-E\left(\bar{t}_{N T}\right)\right)}{\sqrt{\operatorname{var}\left(\bar{t}_{N T}\right)}},
$$

where the values of $E\left(\bar{t}_{N T}\right)$ and $\sqrt{\operatorname{var}\left(\bar{t}_{N T}\right)}$ come from Monte Carlo experiments. When the lag order is non-zero for some cross-sections, Im, et al. $(1997,2003)$ compute the $W_{\bar{t}_{N T}}$ statistic as follows: 


$$
W_{\bar{t}_{N T}}=\frac{\sqrt{N}\left(\bar{t}_{N T}-N^{-1} \sum_{i=1}^{N} E\left(\bar{t}_{i T}\right)\right)}{\sqrt{N^{-1} \sum_{i=1}^{N} \operatorname{var}\left(\bar{t}_{i T}\right)}},
$$

which converges asymptotically to the standard normal distribution.

In both the $H T$ and the IPS tests, the error term $\varepsilon_{i t}$ is independent across $i$. Assuming that the individual time series in the panel are independently distributed over cross sections faces criticism. Specifically, the HT and IPS tests are only valid under the assumption of crosssectional independence. This assumption, however, seldom proves realistic, since it ignores the possibility of short-run co-movements (common cycles) and long-run co-movements (common trends) that characterize industry dynamics. For example, a large literature provides evidence of technological interdependencies and co-movements across firms in the same industry. Panel unitroot tests can lead to spurious results if they fail to account for significant degrees of crosssectional dependence. Pesaran (2004) shows that considerable size distortions emerge ${ }^{12}$ in paneldata analysis, when the hypothesis of cross-sectional independence is violated. To overcome this difficulty, the econometric literature developed various tests that permit cross-sectional dependence. If $N$ is small and $T$ is sufficiently large, then we can model the cross-sectional correlation using the Seemingly Unrelated Regression (SUR) approach. The Lagrange Multiplier (LM) statistic proposed by Breusch and Pagan (1980) tests the diagonality of the errorcovariance matrix of a seemingly unrelated equation system. If $N$ is large, however, we cannot implement the SUR estimation because the error-covariance matrix is rank deficient $(N>T)$. This characterizes our samples.

Pesaran (2004) proposes a cross-sectional dependence $(C D)$ test, which uses the simple

\footnotetext{
${ }^{12}$ Panel unit-root tests will tend to over-reject the null hypothesis of a unit root (i.e., to reject the null whether it is true or not).
} 
average of all pair-wise correlation coefficients. The $C D$ test provides a general test for crosssectional dependence, which, as shown in Pesaran (2004), applies to a large variety of panel data models, including stationary and non-stationary dynamic heterogeneous panel with $T$ small and $N$ large, as is the case for our panel data. The test applies to both balanced and unbalanced panels and is robust to parameter heterogeneity and/or structural breaks, and performs well even in small samples. Under the null hypothesis $H_{0}: \rho_{i t}=\rho_{j t}=\operatorname{corr}\left(\hat{\varepsilon}_{i t}, \hat{\varepsilon}_{j t}\right)=0$ for $i \neq j, \varepsilon_{i t}$ is independent and identically distributed over time periods and across cross-sectional units. Under the alternative hypothesis $H_{1}: \rho_{i t}=\rho_{j t} \neq 0$ for some $i \neq j, \varepsilon_{i t}$ is correlated across crosssections but uncorrelated over time periods. Under the null hypothesis of cross-sectional independence, the $C D$ test statistics are distributed as standard normal for $N$ sufficiently large. The test averages the pair-wise correlation coefficients of the residuals obtained from the individual Augmented Dickey-Fuller $(A D F)$ regression equations. We compute the $C D$ test statistics for a balanced panel as follows:

$$
\begin{aligned}
& C D=\sqrt{\frac{2 T}{N(N-1)}\left(\sum_{i=1}^{N-1} \sum_{j=i+1}^{N} \operatorname{corr}\left(\hat{\varepsilon}_{i}, \hat{\varepsilon}_{j}\right)\right) \text { and }} \\
& \operatorname{corr}\left(\hat{\varepsilon}_{i}, \hat{\varepsilon}_{j}\right)=\frac{\sum_{t=1}^{T} \hat{\varepsilon}_{i t} \hat{\varepsilon}_{j t}}{\left(\sum_{t=1}^{T} \hat{\varepsilon}_{i t}^{2}\right)^{1 / 2}\left(\sum_{t=1}^{T} \hat{\varepsilon}_{j t}^{2}\right)^{1 / 2}}
\end{aligned}
$$

where $\hat{\varepsilon}_{i t}$ are estimated residuals from the Augmented Dickey-Fuller $(A D F)$ regression equations.

Under the null hypothesis of cross-sectional independence, the $C D$ test statistic converges asymptotically to the standardized normal distribution. The $C D$ test also applies to unbalanced panels. In this case, we compute the test statistic as follows: 


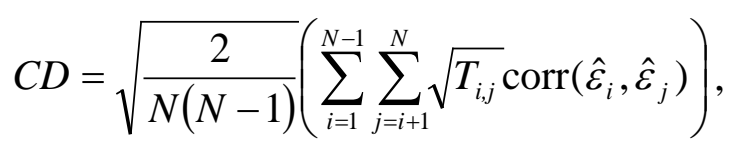

where $T_{i, j}$ equals the number of common time-series observations between units $i$ and $j$.

Pesaran (2007) proposes a cross-sectionally augmented Dickey-Fuller (CADF) panel unit-root test for a balanced panel based on a single common factor specification for the cross-correlation structure. The test augments the $A D F$ equations (3) and (4) with the cross-sectional averages of lagged levels and first differences of the individual series, which filter out the effect of the unobserved common factor. Then, the $C A D F$ test equations are as follows:

$$
\begin{aligned}
& \Delta r_{i t}=a_{i}+\rho_{i} r_{i t-1}+\sum_{j=1}^{p} \gamma_{i j} \Delta r_{i t-j}+b_{i} \bar{r}_{t-1}+\sum_{j=0}^{p} d_{i j} \Delta \bar{r}_{t-j}+\varepsilon_{i t} \text {, and } \\
& \Delta r_{i t}=a_{i}+\rho_{i} r_{i t-1}+\delta_{i} t+\sum_{j=1}^{p} \gamma_{i j} \Delta r_{i t-j}+b_{i} \bar{r}_{t-1}+\sum_{j=0}^{p} d_{j} \Delta \bar{r}_{t-j}+\varepsilon_{i t},
\end{aligned}
$$

respectively, where $\bar{r}_{t}=\frac{1}{N} \sum_{i=1}^{N} r_{i t}$ and $\Delta \bar{r}_{t}=\frac{1}{N} \sum_{i=1}^{N} \Delta r_{i t}$.

The individual-specific test statistic for the hypothesis $H_{0}: \rho_{i}=0$ for a given $i$ equals the $t$-value for $\rho_{i}=0$, called the CADF $t_{i}(N, T)$. The panel unit-root test for the hypothesis $H_{0}: \rho_{i}=0$ for all $i$ against the heterogeneous alternative $H_{1}: \rho_{i}<0$ for some $i$ equals the average of the individual $t_{i}(N, T)$ tests. That is,

$$
C A D F=N^{-1} \sum_{i=1}^{N} t_{i}(N, T)
$$

In addition, to ensure the existence of the first and second moments of the distribution of $t_{i}(N, T)$, Pesaran (2007) constructs a truncated version of the test $\left(C A D F^{*}\right)$ to avoid extreme statistics caused by a small number of sample observations. 


$$
\operatorname{CADF}^{*}(N, T)=\frac{1}{N} \sum_{i=1}^{N} t_{i}^{*}(N, T)
$$

where

$$
t_{i}^{*}(N, T)=\left\{\begin{array}{lc}
t_{i}(N, T) & -K_{1}<t_{i}(N, T)<K_{2} \\
-K_{1} & t_{i}(N, T)<K_{1} \\
-K_{2} & t_{i}(N, T) \geq K_{2}
\end{array}\right.
$$

$K_{1}$ and $K_{2}$ depend upon the deterministic component of the models. Pesaran (2007) provides values for $K_{1}$ and $K_{2}$ obtained by simulations for models with intercept and no trend $\left(K_{1}=6.19\right.$ and $\left.K_{2}=2.61\right)$ and models with intercept and trend $\left(K_{1}=6.42\right.$ and $\left.K_{2}=1.70\right)$.

\section{Empirical results}

We use annual data on 1,136 US public firms belonging to all sectors of the economy over the period 2001 through 2010. The total number of firm-years equals 11,360. The data are obtained from Standard and Poor's Compustat database. We use accounting return series in the analysis. We measure profitability with three of the most extensively used measures -- return on assets $(R O A)$, return on equity (ROE), and return on investment (ROI) (Combs et al., 2005). ROA equals net income divided by total assets, $R O E$ equals net income divided by common equity, and ROI equals net income divided by total invested capital. All ratios in percent use net income before extraordinary items in the numerator. We decompose the sample into ten sectors of the economy, according to the Compustat classification scheme (ECNSEC). The ten sectors include (number of firms in parenthesis): a) Materials (57); b) Consumer Discretionary (208); c) Consumer Staples (67); d) Health Care (102); e) Energy (32); f) Financials (148); g) Industrials (166); h) Information Technology (285); i) Telecommunication Services (50); and j) Utilities (21).

Tables 1 through 4 summarize the results of examining all ten sectors of the economy for 
unit roots using the $H T$ and IPS panel unit-root tests. In each test, we permit two different configurations of the deterministic terms (intercept only and intercept and trend ${ }^{13}$ ) and, in case of the IPS test, different lag lengths for each series. For the IPS tests, we report the robust version, the $W_{\bar{t}}$ test statistic. We also implement the suggestion of Im, et al. (1997, 2003). That is, we assume that in addition to a series-specific intercept and/or trend as given in Equations (3) and (4), a time-specific intercept may exist as well. We control for this possibility by removing for each industry the cross-sectional means from each series. This normalization, by extracting common time-specific or aggregate effects, removes the effect of the business cycle and other macroeconomic shocks. ${ }^{14}$ This correction will not remove the potential effect of correlation between the series, but may reduce it considerably (O’Connell, 1998; Luintel, 2001).

The results (almost) uniformly do not indicate linear hysteretic behavior for any of the three profitability measures. Rather, ample evidence emerges that firm profits exhibit meanreverting stationary processes, whose fluctuations are largely temporary. Only a few significant discrepancies exist in the results provided by both tests. More specifically, the HT test rejects the null hypothesis of a unit-root process for $R O A, R O E$, and $R O I$ at the 1-percent significance level for each of the ten sectors of the economy. This conclusion holds regardless of the inclusion or exclusion of deterministic constants and linear trend. On the other hand, for the intercept only specification, the IPS test rejects the unit-root hypothesis at the 1-percent level for ROE for all sectors; but, for $R O A$ and $R O I$, the test rejects the null at the 1-percent level in all sectors except materials and utilities, for which the test rejects the null of unit root at the 5-percent level. For the

\footnotetext{
${ }^{13}$ With a time trend, mean-reversion implies convergence toward a time-varying mean.

14 This approach differs from the conventional methodology, where researchers normalize profit as a deviation from an economy-wide measure of profitability in year $t$. Using the economy-wide sample mean may produce misleading implications. That is, the profit of a firm in a given industry may not exhibit abnormal behavior with respect to its own sample average, but may exhibit well above- or below-average behavior with respect to the economy-wide average profit.
} 
intercept and trend specification, the test rejects the unit root hypothesis at the 1-percent level for all sectors except utilities, where the test cannot reject the unit root for $R O A$ and $R O I$, but does reject the unit root for $R O E$.

As indicated in the previous section, the HT and the IPS tests assume cross-sectional independence. Thus, the restrictive nature of these tests does not discriminate between stationarity with cross-sectional independence and non-stationarity with cross-sectional dependence. These tests experience well-known large size distortions when cross-sectional independence does not hold. To test whether cross-sectional independence holds in our data, we employ the $C D$ test proposed by Pesaran (2004). For each of the ten sectors, the $C D$ test draws on two specifications: residuals from a fixed effects $A D F$ model with intercept and trend and residuals from a fixed effects $A D F$ model with intercept only. ${ }^{15}$ Tables 5 and 6 report the findings of the $C D$ test. We reject the null hypothesis of no cross-sectional dependence in all cases in both Tables at the 1-percent level, except for the intercept-only findings for Health Care (ROA, ROE, and $R O I$ ) as well as Telecommunication Services (ROE). As the tests clearly indicate, overwhelming evidence of cross-sectional dependence exists in all sectors considered. This plausible result reflects the high degree of cross-sectional dependence induced by intrasectoral links and common shocks.

A potential drawback of the $C D$ test, however, lies in the pair-wise construction of the test, which cannot prevent the possibility that the computed correlations alternate in sign, canceling out each other. In such case, the test would fail to reject the null hypothesis in the presence of cross-sectional dependence. De Hoyos and Sarafidis (2006) suggest computing the average absolute value of the off-diagonal elements of the cross-sectional correlation matrix of

\footnotetext{
${ }^{15}$ These regressions use the raw profitability series that are not adjusted for the mean at each point in time.
} 
residuals, which would help identify cases of cross-sectional dependence when the signs of the correlations alternate. We do not report ${ }^{16}$ the average absolute correlation, but note that in the intercept only case, the average absolute correlation ranges from a minimum of 0.309 (consumer staples) to a maximum of 0.463 (financials), while in the intercept and trend case, the average absolute correlation ranges from a minimum of 0.309 (consumer discretionary) to a maximum of 0.898 (industrials). These results clearly indicate that more than enough evidence exists to support the presence of cross-sectional dependence. In addition, the variability of these estimates suggests that the cross-sectional correlation is heterogeneous rather than homogeneous. This, in turn, may justify the disaggregation of the data to the industry level.

The rejection of the hypothesis of cross-sectional independence implies that the previous panel unit-root tests generate contaminated findings and that we should consider the possible cross-sectional dependence in our panel unit-root tests. Tables 7 and 8 report the results of the truncated version of the $C A D F$ test. ${ }^{17}$ Table 7 presents the results of the intercept only specification, while Table 8 presents the results for the intercept and trend specification. The results of the $C A D F$ test paint a different picture. In Table 7, we cannot reject the null hypothesis that $R O A$ contains a unit root at the 5-percent significance level for 6 sectors - materials, consumer discretionary, consumer staples, health care, energy, and utilities. Similarly, we cannot reject the null hypothesis that $R O E$ contains a unit root at the 5-percent level for 4 sectors materials, consumer discretionary, industrials, and utilities. Finally, we cannot reject the null hypothesis that ROI contains a unit root at the 5-percent level for 6 sectors - materials, consumer discretionary, health care, energy, industrials, and utilities. In Table 8, we cannot reject

\footnotetext{
${ }^{16}$ The findings on average absolute correlations are available on request.

${ }^{17}$ Once again, these regressions use the raw profitability series that are not adjusted for the mean at each point in time.
} 
the null hypothesis that $R O A$ contains a unit root at the 5-percent significance level for 7 sectors - materials, consumer discretionary, health care, energy, financials, industrials, and utilities. Similarly, we cannot reject the null hypothesis that $R O E$ contains a unit root at the 5-percent level for 5 sectors - materials, consumer discretionary, consumer staples, industrials, and utilities. Finally, we cannot reject the null hypothesis that ROI contains a unit root at the 5percent level for 4 sectors - consumer discretionary, consumer staples, financials, and utilities.

In sum, using the $C A D F$ test, we find evidence of non-stationary behavior of profits in eight of the ten sectors, at least for one measure of firm profitability in one of the two Tables. The exceptions - information technology and telecommunication services -- reject random-walk behavior for the three profit measures in both Tables at the 1-percent level. In addition, two sectors - consumer discretionary and utilities -- exhibit non-stationary behavior of firm profits across all three profit measures in both Tables employed in our analysis.

These results reverse, at least in part, the results of the HT and the IPS tests. The failure to reject the unit root hypothesis provides prima facie evidence that is inconsistent with the “competitive environment” hypothesis. The mean-reversion (stationarity) of firm profitability is an important, but only necessary, condition to validate the neoclassical theory of the firm. In contrast, the absence of mean-reversion (non-stationarity) of firm profitability represents strong evidence suggesting that differences in profitability can persist indefinitely.

\section{Conclusions}

Firms display pervasive differences in profitability. Some firms earn profits above the equilibrium level while other firms earn profits below the equilibrium level. Do such differences disappear over time? Are such differences transitory or permanent? We assess this question empirically by applying a variety of unit-root tests. If we can reject the unit-root null hypothesis 
in favor of the alternative hypothesis of stationarity, then such differences in firm profit eventually dissipate and the series revert to their equilibrium levels. Conversely, if we cannot reject the unit root null hypothesis, then such differences in firm profit are permanent and the series never return to their original values. We measure profitability with three of the most extensively used measures: return on assets (ROA), return on equity (ROE), and return on investment (ROI). We partition a balanced panel of 1,136 US public firms for the period 2001 through 2010 into ten sectors of the economy, and we examine the stochastic properties of firm profits in each sector using the unit-root panel data methodology.

In the standard autoregressive approach, the researcher implicitly assumes that profit (loss) reverts to the mean. It remains to determine how quickly the reversion occurs and whether reversion proceeds to no economic profit. That is, the autocorrelation model assumes that firms operate in a competitive environment, where slow reversion and reversion to a non-zero economic profit implies insufficient competition. Persistent profit can come from two different sources - market power and more efficient operation. Such persistence in profit continues only if sufficient barriers insulate firms form competitive forces.

In the unit-root approach, the researcher permits the profit to follow a hysteretic process that does not revert to the mean. Firms do not face a competitive environment. Other factors may affect profit, but these factors must also exhibit hysteretic processes and cointegrate with profit itself. That is, the driving forces behind hysteretic profit, it they exist, must also exhibit a unitroot process. We suggested in the introduction that industries display substantial and persistent differences in productivity (Nelson and Winter, 1982), innovation (Griliches, 1986), skill compositions and wages (Haltiwanger et al., 2007), profitability (Mueller, 1977, 1986), and so on. In sum, profitability may cointegrate with productivity, innovation, skill composition, wages, 
and so on, where each variable exhibits a hysteretic process.

We apply conventional methodologies (Harris and Tzavalis, 1999 and Im, et al., 1997, 2003) for unit roots in panel data. These tests result in the rejection of the unit-root hypothesis in firm profits and support the long-standing “competitive environment” (Mueller, 1986) hypothesis for all sectors, except utilities. These tests, however, encounter a potential problem, which is now widely recognized in the econometric literature, that the assumption of crosssectional independence in the panels is rarely observed in industry data. Cross-sectional dependence reflects a mixture of factors, such as unobservable common stochastic trends, unobservable common factors, common macroeconomic shocks, spatial effects, and spillover effects. Thus, assuming cross-sectional independence proves unrealistic in industry studies. In fact, the $C D$ test (Pesaran, 2004) confirms the existence of cross-sectional dependence in the data.

Cross-sectional dependence does matter and affect substantially the outcome of the tests. Thus, while conventional panel unit-root tests suggest that profitability exhibits mean-reverting (stationary) behavior, tests that account for cross-sectional dependence (Pesaran, 2007) no longer consistently rejects the null hypothesis on non-mean-reverting (non-stationary) behavior for many sectors of the US economy. Thus, in those sectors, we cannot describe the dynamics of firm profits by mean-reverting dynamics. Rather, in contrast to previous research which suggests that firm profitability is persistent but stationary, we uncover evidence of hysteretic features in the dynamics of profits in many sectors. This is inconsistent with the "competitive environment" hypothesis. Furthermore, the inability to reject the unit-root hypothesis for all sectors of the US economy indicates that sectors of the US economy see differences in profitability that persist indefinitely and where competitive pressures never erode such differences. 
In sum, we strongly support the competitive environment hypothesis in two sectors information technology and telecommunications services - that conventional wisdom suggests exhibit much innovation and competition in the last decade. We strongly reject the competitive environment hypothesis in two other sectors - consumer discretionary and utilities. Utilities fall under the umbrella of a frequently regulated industry, although less so in the last decade. The other six sectors exhibit evidence of both stationary and hysteretic behavior, depending on the measure of profitability and/or the data generating process.

We offer one caution on our findings. To wit, although we disaggregated our analysis to industry sector levels, we may not have disaggregated enough to reach the truly industry level required to test he competitive environment hypothesis. 


\section{References:}

Abowd, J. M., Haltiwanger, J., Jarmin, R., Lane, J. I., Lengermann, P., McCue, K., McKinney, K., and Sandusky, K., (2005). The Relation among Human Capital, Productivity, and Market Value: Building Up from Micro Evidence. In Measuring Capital in the New Economy, Studies in Income and Wealth, C. Corrado, J. Haltiwanger, and D. Sichel (Eds), 65, 153-204, University of Chicago Press, Chicago, 2005.

Arellano, M., and Bond, S., (1991). Some Tests of Specification for Panel Data: Monte Carlo Evidence and an Application to Employment Equations, Review of Economic Studies, 58, 277-297.

Aslan, A, Kula, F. and Kaplan, M., (2010). New Evidence on The Persistence of Profit in Turkey with First and Second Generation Panel Unit Root Test. METU Studies in Development 37, 25-40.

Aslan, A., Koksal, K, and Ocal, O, (2011). Competitive Environment Hypothesis in Turkish Banking System. International Journal of Economics and Financial Issues 1, 74-77.

Bain, J. S., (1951). Relation of Profit Rate to Industry Concentration: American Manufacturing 1936-1940. Quarterly Journal of Economics 65, 293-324.

Bain, J. S., (1956). Barriers to New Competition, Cambridge, MA, Harvard University Press.

Bentzen, J., Madsen, E., Smith, V., and Dilling-Hansen, M., (2005). Persistence in Corporate Performance? Empirical Evidence from Panel Unit Root Tests. Empirica 32, 217-230.

Breitung, J., and Pesaran, M. H. (2008). Unit roots and cointegration in panels. In The Econometrics of Panel Data, L. Matyas and P. Sevestre (Eds.),. Third edition, Ch. 9, 279322. Kluwer Academic Publishers.

Breusch, T. S., and Pagan, A. R., (1980). The Lagrange Multiplier Test and Its Applications to Model Specification in Econometrics. Review of Economic Studies 47, 239-254.

Cameron, A. C., and Trivedi, P. K., (2005). Microeconometrics: Methods and Applications. Cambridge University Press.

Collins, N. R., and Preston, L. E., (1969). Price-Cost Margins and Industry Structure. Review of Economics and Statistics 51, 271-286.

Comanor, W. S., and Wilson, T. A., (1967). Advertising, Markets Structure and Performance. Review of Economics and Statistics 49, 423-440.

Combs, J., Crook, T., and Shook, C., (2005). The Dimensionality of Organizational Performance and its Implications for Strategic Management Research. In Research Methodology in Strategy and Management, Vol. 2, D. J. Ketchen and D. D. Bergh (Eds.). Emerald Group Publishing Limited, Elsevier, 259-286. 
Cuaresma, J. C., and Gschwandtner, A., (2005). The Competitive Environment Hypothesis Revisited: Nonlinearity, Nonstationarity and Profit Persistence. Applied Economics 38, 465-472.

Cuaresma, J. C. and Gschwandtner, A., (2008). Tracing the Dynamics of Competition: Evidence from Company Profits. Economic Inquiry 46, 208-213.

Cubbin, J. and Geroski, P. A., (1990). The Persistence of Profits in the United Kingdom. In The Dynamics of Company Profits: An International Comparison, D. C. Mueller (Ed.). Cambridge University Press, Cambridge, 147-67.

Cross, R., Grinfeld, M. and Lamba, H. (2009). Hysteresis and Economics. IEEE Control Systems Magazine 29, 30-43.

Dechow, P. M., Hutton, A. P., and Sloan, R. G., (1999). An Empirical Assessment of the Residual Income Valuation Model. Journal of Accounting and Economics 26, 1-34.

De Hoyos, R. E., and Sarafidis, V., (2006). Testing for Cross-sectional Dependence in Panel Data Models. The Stata Journal 6, 482-496.

Franz, W., (1990). Special Issue on Hysteresis Effects in Economic Models. Empirical Economics 15, 109-125.

Fuchs, V. R., (1961). Integration, Concentration and Profits in Manufacturing Industry. Quarterly Journal of Economics 75, 278-291.

Geroski, P., and Jacquemin, A., (June 1988). The Persistence of Profits: A European Perspective, Economic Journal 98, 375-389.

Geroski, P., (1990). Modelling Persistent Profitability. In The Dynamics of Company Profits: An International Comparison, D. C. Mueller (Ed.). Cambridge: Cambridge University Press, 15-34.

Glen, J., Lee, K., and Singh, A., (2001). Persistence of Profitability and Competition in Emerging Markets. Economics Letters 72, 247-253.

Goddard, J. A., and Wilson, J. O. S., (1999). The Persistence of Profit: A New Empirical Interpretation. International Journal of Industrial Organization 17, 663-687.

Goddard, J. A., Molyneux, P., and Wilson, J. O. S., (2004). The Profitability of European Banks: A Cross-Sectional and Dynamic Panel Analysis, The Manchester School 72, 363-381.

Gordon, R. J., (1989). Hysteresis in History: Was there Ever a Phillips Curve? American Economic Review 79, 220-225. 
Griliches, Z., (1986). Productivity, R\&D and Basic Research at the Firm Level in 1970's. American Economic Review 76, 141-154.

Gschwandtner, A., (2005). Profit Persistence in the 'Very’ Long Run: Evidence from Survivors and Exiters. Applied Economics 37, 793-806.

Gschwandtner, A., (2012). Evolution of Profit Persistence in the US: Evidence from Three Periods. The Manchester School 80, 172-209.

Gschwandtner, A. and Hauser, M., (2008). Modelling Profit Series: Nonstationarity and long Memory. Applied Economics 40, 1475-1482.

Haltiwanger, J. C., Lane, J. I., and Spletzer, J. R., (1999). Productivity Differences across Employers: The Roles of Employer Size, Age and Human Capital. American Economic Review 89, 94-98.

Haltiwanger, J. C., Lane, J. I., and Spletzer, J. R., (2007). Wages, Productivity and the Dynamic Interaction of Businesses and Workers. Labor Economics 14, 575-602.

Harris, R. D. F., and Tzavalis, E., (1999). Inference for Unit Roots in Dynamic Panels where the Time Dimension Is Fixed. Journal of Econometrics 91, 201-226.

Im, K. S., Pesaran, M. H., and Shin, Y., (1997). Testing for Unit Roots in Heterogeneous Panels. Cambridge Working Papers in Economics, Department of Applied Economics, University of Cambridge.

Im, K. S., Pesaran, M. H., and Shin, Y., (2003). Testing for Unit Roots in Heterogeneous Panels. Journal of Econometrics 115, 53-74.

Jenny, F. Y., and Weber, A. P., (1990). The Persistence of Profits in France. In The Dynamics of Company Profits, D. C. Mueller (Ed.). Cambridge: Cambridge University Press, 123-128.

Jönsson, K., (2005). Cross-sectional Dependency and Size Distortion in a Small-sample Homogeneous Panel Data Unit Root Test. Oxford Bulletin of Economics and Statistics 67, 369-392.

Kambhampati, U. S., (1995). The Persistence of Profit Differentials in Indian Industry. Applied Economics 27, 353-361

Kamerschen, D. R., (1969). The Determination of Profit Rates in "Oligopolistic" Industries. Journal of Business 42, 293-301.

Khemani, R. S., and Shapiro, D. M., (1990). The Persistence of Predictability in Canada. In The Dynamics of Company Profits: An International Comparison, D. C. Mueller (Ed.). Cambridge University Press, Cambridge, 77-104. 
León-Ledesma, M. A., and McAdam, P., (2004). Unemployment, Hysteresis and Transition. Scottish Journal of Political Economy 51, 377-401.

Levin, A., Lin, C. F., and Chu, C. S. J., (2002). Unit Root Tests in Panel Data: Asymptotic and Finite-Sample Properties. Journal of Econometrics 108, 1-24

Levinson, H., (1960). Post War Movements in Prices and Wages in Manufacturing Industries, Joint Economic Committee, Study of Income, Employment, and Prices. Study Paper No. 21, Washington, Government Printing Office.

Lieberman, M. B., and Montgomery, D. B., (1988). First-mover Advantages. Strategic Management Journal 9, 41-58.

Lipczinsky, J., and Wilson, J., (2001). Industrial Organization: An Analysis of Competitive Markets. Prentice Hall, UK.

Luintel, K. B., (2001). Heterogeneous Panel Unit Root Tests and Purchasing Power Parity. The Manchester School (Supplement) 69, 42-56.

Madsen, E., (2010). Unit Root Inference in Panel Data Models where the Time-series Dimension Is Fixed: A Comparison of Different Tests. Econometrics Journal 13, 63-94.

Marshall, A., (1890). Principles of Economics, Macmillan: London.

McMillan, D. G., and Wohar, M. E., (2011). Profit Persistence Revisited: The Case of the UK. The Manchester School 79, 510-527.

Mueller, D. C., (1977). The Persistence of Profits Above the Norm. Economica 44, 369-380.

Mueller, D. C., (1986). Profits in the Long Run. Cambridge University Press, Cambridge.

Mueller, D. C., (Ed.), (1990). The Dynamics of Company Profits. Cambridge, England: Cambridge University Press.

Mueller, D. C., (1997). Merger Policy in the United States: A Reconsideration. Review of Industrial Organization 12, 655-685.

Nelson, R., and Winter, S., (1982). An Evolutionary Theory of Economic Change. Cambridge, MA: The Bellknap Press of Harvard University Press.

O'Connell, P. G. J., (1998). The Overvaluation of Purchasing Power Parity. Journal of International Economics 44, 1-19.

Odagiri, H., and Yamawaki, H., (1986). A Study of Company Profit-Rate Time Series: Japan and the United States. International Journal of Industrial Organization 4, 1-23. 
Odagiri, H., and Yamawaki, H., (1990). The Persistence of Profits in Japan. In The Dynamics of Company Profits, D. C. Mueller (Ed.). Cambridge: Cambridge University Press, 129-146.

Ohlson, J., (1995). Earnings, Book Values, and Dividends in Equity Valuation. Contemporary Accounting Research 11, 661-687.

Pérez-Alonso, A., and Di Sanzo, S., (2011). Unemployment and Hysteresis: A Nonlinear Unobserved Components Approach. Studies in Nonlinear Dynamics \& Econometrics 15 http://www.bepress.com/snde/vol15/iss1/art2.

Pesaran, M. H., (2004). General Diagnostic Tests for Cross Section Dependence in Panels. Cambridge Working Papers in Economics, Department of Applied Economics, University of Cambridge.

Pesaran, M. H., (2007). A Simple Panel Unit Root Test in the Presence of Cross-section Dependence. Journal of Applied Econometrics 22, 265-312.

Resende, M., (2006). Profit Persistence in Brazil: A Panel Data Study. Estudos Economicos 36, 115-126.

Schohl, F., (1990). Persistence of Profits in the Long Run. International Journal of Industrial Organization 8, 385-404.

Schumpeter, J. A., (1934). The Theory of Economic Development. Cambridge, MA: Harvard University Press.

Schumpeter, J. A., (1950). Capitalism, Socialism and Democracy. New York: Harper and Row.

Schwalbach, J., Grasshoff, U., and Mahmood, T., (1989). The Dynamics of Corporate Profits. European Economic Review 33, 1625-1639.

Schwartzman, D., (1959). The Effects of Monopoly on Price. Journal of Political Economy 67, 352-362.

Siddique, A., and Sweeney, R. J., (2000). Earnings, Book Value and Residual Income: Implications of Time Series Properties. Georgetown University: Working Paper, McDonough School of Business.

Spence, M., (1981). The Learning Curve and Competition. The Bell Journal of Economics 12, 49-70.

Stephan, A., and Tsapin, A., (2008). Persistence and Determinants of Firm Profit in Emerging Markets. Applied Economics Quarterly 54, 231-253.

Strauss, J., and Yogit, R., (2003). Shortfalls of Panel Unit Root Testing. Economics Letters 81, 309-313. 
Tippett, M., (1990). An Induced Theory of Financial Ratios. Accounting and Business Research 21, 77-85.

Tippet, M., and Whittington, G., (1995). An Empirical Evaluation of an Induced Theory of Financial Ratios. Accounting and Business Research 25, 209-238.

Waring, G., (1996). Industry Differences in the Persistence of Firm-specific Returns. American Economic Review 86, 1253-1265.

Weiss, L. W., (1963). Average Concentration Ratios and Industry Performance. Journal of Industrial Economics 11, 237-254.

Whittington, G., and Tippett, M., (1999). The Components of Accounting Ratios as Cointegrated Variables. Journal of Business Finance and Accounting 26, 1245-1273.

Yurtoglu, B. B., (2004). Persistence of Firm-Level Profitability in Turkey. Applied Economics 36, 615-625. 
Table 1: Harris and Tzavalis panel unit-root test results (intercept only).

\begin{tabular}{|l|c|c|c|}
\hline Economic Sector & $\boldsymbol{R O A}$ & $\boldsymbol{R O E}$ & $\boldsymbol{R O I}$ \\
\hline \multirow{2}{*}{ Materials } & $-19.863^{*}$ & $-13.377^{*}$ & $-11.894^{*}$ \\
& $(0.000)$ & $(0.000)$ & $(0.000)$ \\
\hline \multirow{2}{*}{ Consumer Discretionary } & $-26.966^{*}$ & $-37.355^{*}$ & $-34.385^{*}$ \\
& $(0.000)$ & $(0.000)$ & $(0.000)$ \\
\hline \multirow{2}{*}{ Consumer Staples } & $-12.590^{*}$ & $-16.595^{*}$ & $-10.755^{*}$ \\
& $(0.000)$ & $(0.000)$ & $(0.000)$ \\
\hline \multirow{2}{*}{ Health Care } & $-18.252^{*}$ & $-28.776^{*}$ & $-23.791^{*}$ \\
\hline \multirow{2}{*}{ Energy } & $(0.000)$ & $(0.000)$ & $(0.000)$ \\
\hline \multirow{2}{*}{ Financials } & $-17.154^{*}$ & $-4.681^{*}$ & $-4.679^{*}$ \\
\hline \multirow{2}{*}{ Industrials } & $(0.000)$ & $(0.000)$ & $(0.000)$ \\
\hline \multirow{2}{*}{ Information Technology } & $-24.369^{*}$ & $-23.792^{*}$ & $-23.012^{*}$ \\
& $(0.000)$ & $(0.000)$ & $(0.000)$ \\
\hline \multirow{2}{*}{ Telecommunication Services } & $-16.518^{*}$ & $-39.698^{*}$ & $-36.642^{*}$ \\
& $(0.000)$ & $(0.000)$ & $(0.000)$ \\
\hline Utilities & $-42.697^{*}$ & $-47.004^{*}$ & $-46.413^{*}$ \\
& $(0.000)$ & $(0.000)$ & $(0.000)$ \\
\hline
\end{tabular}

Note: The ten sectors include (number of firms in parenthesis): Materials (57); Consumer Discretionary (208); Consumer Staples (67); Health Care (102); Energy (32); Financials (148); Industrials (166); Information Technology (285); Telecommunication Services (45); and Utilities (21). The profit measures include return on assets $(R O A)$, return on equity (ROE), and return on investment (ROI). The DGP includes heterogeneous fixed effects and no trend. The test statistic equals $\sqrt{N}\left(\hat{\rho}_{W G}-1-B_{2}\right)$, which is asymptotically normally distributed with $\mu=0$ and $\sigma^{2}=C_{2}$, where $\hat{\rho}_{W G}$ equals the $W G$ estimator, $B_{2}=-3(T+1)^{-1}$, and $C_{2}=3\left(17 T^{2}-20 T+17\right)\left(5(T-1)(T+1)^{3}\right)^{-1}$. The p-values appear in parentheses under test statistics.

* means significant at the 1-percent level.

** means significant at the 5-percent level. 
Table 2: Harris and Tzavalis panel unit-root test results (intercept and trend)

\begin{tabular}{|l|c|c|c|}
\hline Economic Sector & $\boldsymbol{R O A}$ & $\boldsymbol{R O E}$ & $\boldsymbol{R O I}$ \\
\hline Materials & $-17.291^{*}$ & $-10.847^{*}$ & $-10.076^{*}$ \\
& $(0.000)$ & $(0.000)$ & $(0.000)$ \\
\hline \multirow{2}{*}{ Consumer Discretionary } & $-15.678^{*}$ & $-24.136^{*}$ & $-20.449^{*}$ \\
& $(0.000)$ & $(0.000)$ & $(0.000)$ \\
\hline \multirow{2}{*}{ Consumer Staples } & $-9.547^{*}$ & $-6.593^{*}$ & $-9.096^{*}$ \\
& $(0.000)$ & $(0.000)$ & $(0.000)$ \\
\hline \multirow{2}{*}{ Health Care } & $-9.051^{*}$ & $-15.380^{*}$ & $-11.376^{*}$ \\
& $(0.000)$ & $(0.000)$ & $(0.000)$ \\
\hline \multirow{2}{*}{ Energy } & $-12.111^{*}$ & $-4.468^{*}$ & $-4.468^{*}$ \\
& $(0.000)$ & $(0.000)$ & $(0.000)$ \\
\hline Financials & $-11.154^{*}$ & $-14.292^{*}$ & $-10.056^{*}$ \\
& $(0.000)$ & $(0.000)$ & $(0.000)$ \\
\hline \multirow{2}{*}{ Industrials } & $-7.832^{*}$ & $-31.4768^{*}$ & $-28.773^{*}$ \\
& $(0.000)$ & $(0.000)$ & $(0.000)$ \\
\hline \multirow{2}{*}{ Information Technology } & $-29.473^{*}$ & $-32.055^{*}$ & $-33.512^{*}$ \\
& $(0.000)$ & $(0.000)$ & $(0.000)$ \\
\hline Utilities & $-13.698^{*}$ & $-13.607^{*}$ & $-15.034^{*}$ \\
& $(0.000)$ & $(0.000)$ & $(0.000)$ \\
\hline \multirow{2}{*}{ Selommunication Services } & $-4.550^{*}$ & $-7.658^{*}$ & $-4.639^{*}$ \\
& $(0.000)$ & $(0.000)$ & $(0.000)$ \\
\hline
\end{tabular}

Note: See Table 1. The DGP includes heterogeneous fixed effects and linear trend. the test statistic equals $\sqrt{N}\left(\hat{\rho}_{W G}-1-B_{3}\right)$, which is asymptotically normally distributed with $\quad \mu=0$ and $\sigma^{2}=C_{3}$, where $B_{3}=-15(2(T+2))^{-1} \quad$ and $C_{3}=15\left(193 T^{2}-728 T=1147\right)\left(112(T-2)(T+2)^{3}\right)^{-1}$. The p-values appear in parentheses under test statistics.

* means significant at the 1-percent level.

** means significant at the 5-percent level. 
Table 3: Im, Pesaran, and Shin panel unit-root test results (intercept only).

\begin{tabular}{|l|c|c|c|}
\hline Economic Sector & $\boldsymbol{R O A}$ & $\boldsymbol{R O E}$ & $\boldsymbol{R O I}$ \\
\hline \multirow{2}{*}{ Materials } & $-6.656^{*}$ & $-2.974^{*}$ & $-2.260^{*}$ \\
& $(0.000)$ & $(0.002)$ & $(0.012)$ \\
\hline \multirow{2}{*}{ Consumer Discretionary } & $-9.908^{*}$ & $-12.781^{*}$ & $-12.129^{*}$ \\
& $(0.000)$ & $(0.000)$ & $(0.000)$ \\
\hline \multirow{2}{*}{ Consumer Staples } & $-8.213^{*}$ & $-23.179^{*}$ & $-8.745^{*}$ \\
& $(0.000)$ & $(0.000)$ & $(0.000)$ \\
\hline \multirow{2}{*}{ Health Care } & $-10.562^{*}$ & $-10.491^{*}$ & $-12.240^{*}$ \\
& $(0.000)$ & $(0.000)$ & $(0.000)$ \\
\hline \multirow{2}{*}{ Energy } & $-7.556^{*}$ & $-4.809^{*}$ & $-4.981^{*}$ \\
\multirow{2}{*}{ Financials } & $(0.000)$ & $(0.000)$ & $(0.000)$ \\
\hline \multirow{2}{*}{ Industrials } & $-3.847^{*}$ & $-3.475^{*}$ & $-2.880^{*}$ \\
& $(0.000)$ & $(0.000)$ & $(0.002)$ \\
\hline Information Technology & $-8.991^{*}$ & $-4.619^{*}$ & $-12.311^{*}$ \\
& $(0.000)$ & $(0.000)$ & $(0.000)$ \\
\hline \multirow{2}{*}{ Telecommunication Services } & $-20.835^{*}$ & $-27.639^{*}$ & $-27.822^{*}$ \\
& $(0.000)$ & $(0.000)$ & $(0.000)$ \\
\hline \multirow{2}{*}{ Utilities } & $-9.017^{*}$ & $-8.3236^{*}$ & $-13.733^{*}$ \\
& $(0.000)$ & $(0.000)$ & $(0.000)$ \\
\hline
\end{tabular}

Note: See Table 1. The Table reports the $W_{\bar{t}_{N T}}$ statistic, $W_{\bar{t}_{N T}}=\frac{\sqrt{N}\left(\overline{t_{N T}}-N^{-1} \sum_{i=1}^{N} E\left(\overline{t_{i T}}\right)\right)}{\sqrt{N^{-1} \sum_{i=1}^{N} \operatorname{var}\left(\overline{t_{i T}}\right)}}$, which converges asymptotically to the standard normal distribution. The p-values appear in parentheses under test statistics.

* $\quad$ means significant at the 1-percent level.

** means significant at the 5-percent level. 
Table 4: $\quad$ Im, Pesaran, and Shin panel unit-root test results (intercept and trend)

\begin{tabular}{|l|c|c|c|}
\hline Economic Sector & $\boldsymbol{R O A}$ & $\boldsymbol{R O E}$ & $\boldsymbol{R O I}$ \\
\hline Materials & $-4.418^{*}$ & $-4.489^{*}$ & $-3.396^{*}$ \\
& $(0.000)$ & $(0.000)$ & $(0.000)$ \\
\hline \multirow{2}{*}{ Consumer Discretionary } & $-10.146^{*}$ & $-13.807^{*}$ & $-11.178^{*}$ \\
& $(0.000)$ & $(0.000)$ & $(0.000)$ \\
\hline \multirow{2}{*}{ Consumer Staples } & $-6.620^{*}$ & $-15.038^{*}$ & $-12.584^{*}$ \\
& $(0.000)$ & $(0.000)$ & $(0.000)$ \\
\hline \multirow{2}{*}{ Health Care } & $-5.544^{*}$ & $-12.546^{*}$ & $-8.948^{*}$ \\
& $(0.000)$ & $(0.000)$ & $(0.000)$ \\
\hline \multirow{2}{*}{ Energy } & $-8.899^{*}$ & $-3.381^{*}$ & $-3.176^{*}$ \\
& $(0.000)$ & $(0.000)$ & $(0.000)$ \\
\hline \multirow{2}{*}{ Financials } & $-7.894^{*}$ & $-3.785^{*}$ & $-3.977^{*}$ \\
& $(0.000)$ & $(0.000)$ & $(0.000)$ \\
\hline \multirow{2}{*}{ Industrials } & $-4.329^{*}$ & $-2.904^{*}$ & $-10.830^{*}$ \\
& $(0.000)$ & $(0.001)$ & $(0.000)$ \\
\hline \multirow{2}{*}{ Information Technology } & $-15.733^{*}$ & $-21.183^{*}$ & $-24.209^{*}$ \\
& $(0.000)$ & $(0.000)$ & $(0.000)$ \\
\hline \multirow{2}{*}{ Telecommunication Services } & $-12.778^{*}$ & $-8.902^{*}$ & $-10.361^{*}$ \\
& $(0.000)$ & $(0.000)$ & $(0.000)$ \\
\hline \multirow{2}{*}{ Utilities } & -1.157 & $-3.242^{*}$ & -0.621 \\
& $(0.123)$ & $(0.000)$ & $(0.267)$ \\
\hline
\end{tabular}

Note: See Table 1. The Table reports the $W_{\bar{t}_{N T}}$ statistic, $W_{\bar{t}_{N T}}=\frac{\sqrt{N}\left(\bar{t}_{N T}-N^{-1} \sum_{i=1}^{N} E\left(\bar{t}_{i T}\right)\right)}{\sqrt{N^{-1} \sum_{i=1}^{N} \operatorname{var}\left(\bar{t}_{i T}\right)}}$, which converges asymptotically to the standard normal distribution. The -values appear in parentheses under test statistics.

* means significant at the 1-percent level.

** means significant at the 5-percent level. 
Table 5: $\quad C D$ test results (intercept only).

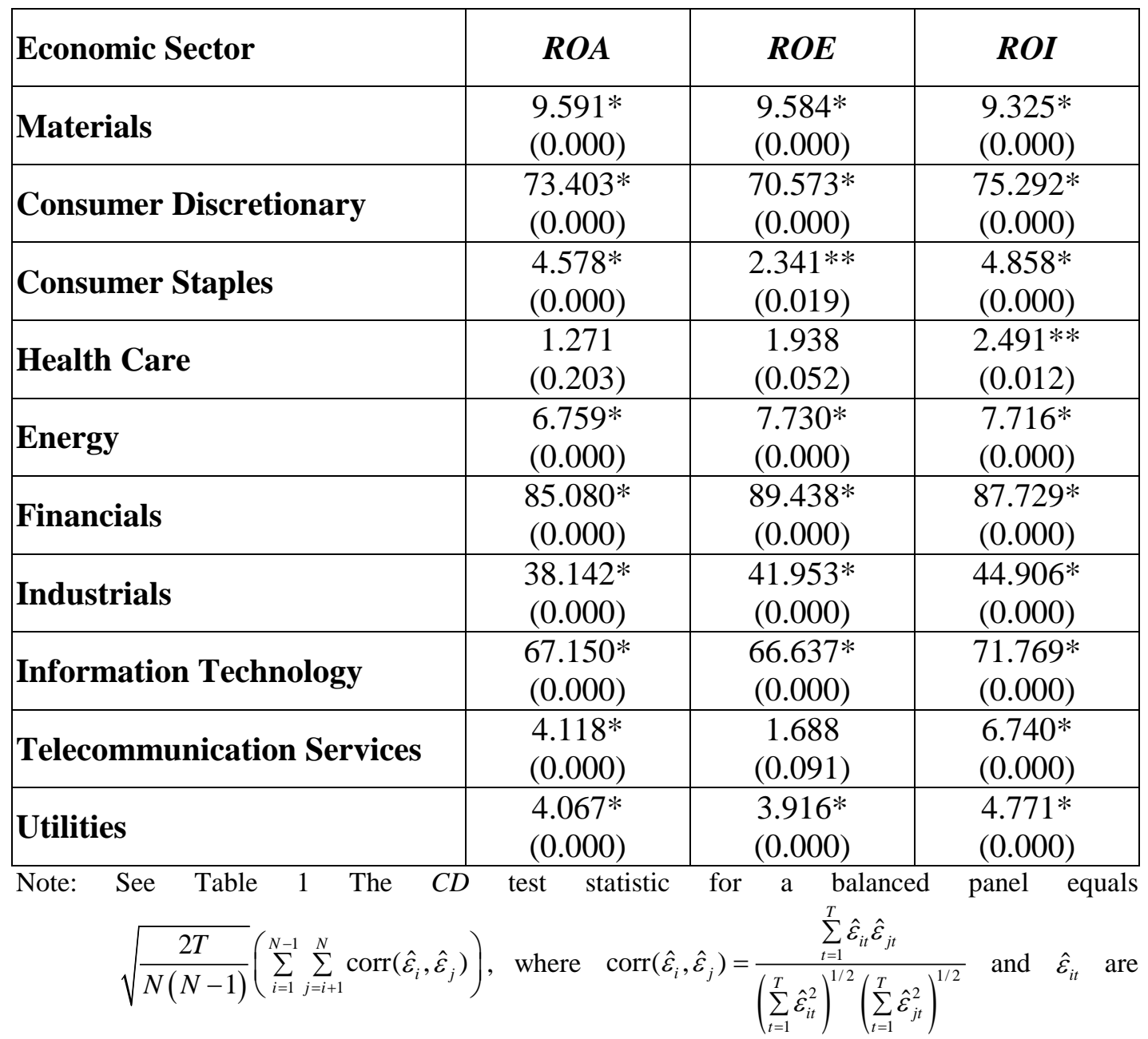

estimated residuals from the Augmented Dickey-Fuller $(A D F)$ regression equations. Under the null hypothesis of cross-sectional independence, the $C D$ test statistic converges asymptotically to the standardized normal distribution. The $C D$ test for an unbalanced panels equals $\sqrt{\frac{2}{N(N-1)}}\left(\sum_{i=1}^{N-1} \sum_{j=i+1}^{N} \sqrt{T_{i, j}} \operatorname{corr}\left(\hat{\varepsilon}_{i}, \hat{\varepsilon}_{j}\right)\right)$, where $T_{i, j}$ equals the number of common time-series observations between units $i$ and $j$. The p-values appear in parentheses under test statistics.

* means significant at the 1-percent level.

** means significant at the 5-percent level. 
Table 6: $\quad C D$ test results (intercept and trend).

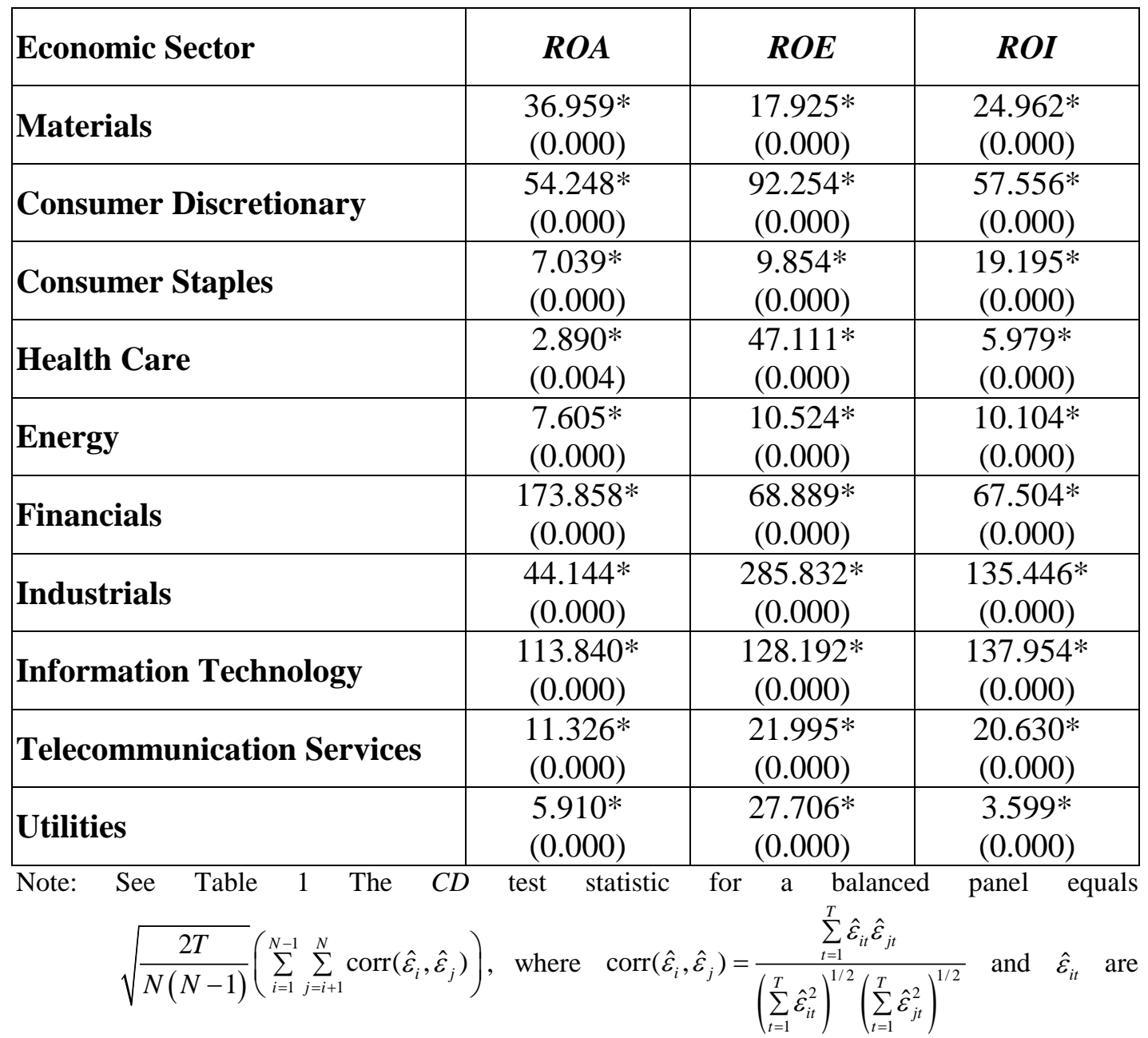

estimated residuals from the Augmented Dickey-Fuller $(A D F)$ regression equations. Under the null hypothesis of cross-sectional independence, the $C D$ test statistic converges asymptotically to the standardized normal distribution. The $C D$ test for an unbalanced panels equals $\sqrt{\frac{2}{N(N-1)}}\left(\sum_{i=1}^{N-1} \sum_{j=i+1}^{N} \sqrt{T_{i, j}} \operatorname{corr}\left(\hat{\varepsilon}_{i}, \hat{\varepsilon}_{j}\right)\right)$, where $T_{i, j}$ equals the number of common time-series observations between units $i$ and $j$. The p-values appear in parentheses under test statistics.

* means significant at the 1-percent level.

** means significant at the 5-percent level. 
Table 7: $\quad$ CADF unit-root test results (intercept only).

\begin{tabular}{|l|c|c|c|}
\hline Economic Sector & $\boldsymbol{R O A}$ & $\boldsymbol{R O E}$ & $\boldsymbol{R O I}$ \\
\hline Materials & -1.239 & -1.512 & -0.996 \\
& $(0.108)$ & $(0.065)$ & $(0.160)$ \\
\hline \multirow{2}{*}{ Consumer Discretionary } & -0.354 & 0.436 & 2.856 \\
& $(0.362)$ & $(0.668)$ & $(0.998)$ \\
\hline \multirow{2}{*}{ Consumer Staples } & -1.503 & $-1.658^{* *}$ & $-2.648^{*}$ \\
& $(0.066)$ & $(0.049)$ & $(0.004)$ \\
\hline \multirow{2}{*}{ Health Care } & 0.482 & $-1.682^{* *}$ & -0.487 \\
\hline \multirow{2}{*}{ Energy } & $(0.685)$ & $(0.046)$ & $(0.313)$ \\
\hline \multirow{2}{*}{ Financials } & 0.703 & $-1.926^{* *}$ & 0.050 \\
& $(0.759)$ & $(0.027)$ & $(0.520)$ \\
\hline \multirow{2}{*}{ Industrials } & $-1.943^{* *}$ & $-3.486^{*}$ & $-4.716^{*}$ \\
& $(0.026)$ & $(0.000)$ & $(0.000)$ \\
\hline Information Technology & $-4.460^{*}$ & -1.307 & -1.235 \\
& $(0.000)$ & $(0.096)$ & $(0.108)$ \\
\hline \multirow{2}{*}{ Telecommunication Services } & $-4.969^{*}$ & $-4.269^{*}$ & $-3.949^{*}$ \\
& $(0.000)$ & $(0.000)$ & $(0.000)$ \\
\hline Utilities & $-3.293^{*}$ & $-5.817^{*}$ & $-2.707^{*}$ \\
& $(0.000)$ & $(0.000)$ & $(0.003)$ \\
\hline
\end{tabular}

Note: The truncated $\operatorname{CADF}^{*}(N, T)$ test, avoiding extreme statistics caused by a small number of sample observations, equals $\frac{1}{N} \sum_{i=1}^{N} t_{i}^{*}(N, T)$, where $t_{i}^{*}(N, T)= \begin{cases}t_{i}(N, T) & -K_{1}<t_{i}(N, T)<K_{2} \\ -K_{1} & t_{i}(N, T)<K_{1} \\ -K_{2} & t_{i}(N, T) \geq K_{2}\end{cases}$

$K_{1}$ and $K_{2}$ depend upon the deterministic component of the models. Pesaran (2007) simulates results in models with intercept and no trend $\left(K_{1}=6.19\right.$ and $\left.K_{2}=2.61\right)$ and in models with intercept and trend $\left(K_{1}=6.42\right.$ and $\left.K_{2}=1.70\right)$. The p-values appear in parentheses under test statistics.

* means significant at the 1-percent level.

** means significant at the 5-percent level. 
Table 8: $\quad C A D F$ unit-root test results (intercept and trend).

\begin{tabular}{|l|c|c|c|}
\hline Economic Sector & $\boldsymbol{R O A}$ & $\boldsymbol{R O E}$ & $\boldsymbol{R O I}$ \\
\hline \multirow{2}{*}{ Materials } & -0362 & -4.040 & $-2.525^{*}$ \\
& $(0.359)$ & $(0.065)$ & $(0.006)$ \\
\hline \multirow{2}{*}{ Consumer Discretionary } & -1.259 & -0.005 & 0.666 \\
& $(0.104)$ & $(0.498)$ & $(0.747)$ \\
\hline \multirow{2}{*}{ Consumer Staples } & $-3.769^{*}$ & -0.109 & -1.071 \\
& $(0.000)$ & $(0.457)$ & $(0.142)$ \\
\hline \multirow{2}{*}{ Health Care } & 0.118 & $-3.434^{*}$ & $-1.749^{*}$ \\
\hline \multirow{2}{*}{ Energy } & $(0.547)$ & $(0.000)$ & $(0.004)$ \\
\hline \multirow{2}{*}{ Financials } & 0.025 & $-3.203^{*}$ & $-3.031^{*}$ \\
\hline \multirow{2}{*}{ Industrials } & $(0.510)$ & $(0.001)$ & $(0.001)$ \\
\hline \multirow{2}{*}{ Information Technology } & 0.009 & $-4.059^{*}$ & -0.578 \\
& $(0.504)$ & $(0.000)$ & $(0.282)$ \\
\hline \multirow{2}{*}{ Telecommunication Services } & -1.156 & -1.204 & $-2.145^{*}$ \\
\hline Utilities & $(0.124)$ & $(0.114)$ & $(0.016)$ \\
\hline
\end{tabular}

Note: The truncated $\operatorname{CADF}^{*}(N, T)$ test, avoiding extreme statistics caused by a small number of sample observations, equals $\frac{1}{N} \sum_{i=1}^{N} t_{i}^{*}(N, T)$, where $t_{i}^{*}(N, T)= \begin{cases}t_{i}(N, T) & -K_{1}<t_{i}(N, T)<K_{2} \\ -K_{1} & t_{i}(N, T)<K_{1} \\ -K_{2} & t_{i}(N, T) \geq K_{2}\end{cases}$

$K_{1}$ and $K_{2}$ depend upon the deterministic component of the models. Pesaran (2007) simulates results in models with intercept and no trend $\left(K_{1}=6.19\right.$ and $\left.K_{2}=2.61\right)$ and in models with intercept and trend $\left(K_{1}=6.42\right.$ and $\left.K_{2}=1.70\right)$. The p-values appear in parentheses under test statistics.

* $\quad$ means significant at the 1-percent level.

** means significant at the 5-percent level. 